\title{
THROMBOELASTOMETRY AS A GUIDE IN A PATIENT SCHEDULED FOR THORACIC SURGERY WITH AN ACQUIRED DYSFIBRINOGENEMIA DUE TO AN ACQUIRED INHIBITOR THAT PRODUCED A DELAY OF FIBRINOPEPTIDE B RELEASE
} Parera A., Diaz R., Unzueta M.C., Moral M.V

\section{Hospital de Sant Pau, Dept. of Anaesthesiology \& Pain Medicine, Barcelona, Spain}

\section{Background}

Acquired inhibitors that interfere directly with fibrin formation are rare and the vast majority occur in patients with autoimmune disease, malignancy or without underlying causes. In our case, routine coagulation tests have a low predictability of bleeding and tromboelastometry may improve hemostatic monitoring.

\section{Case report}

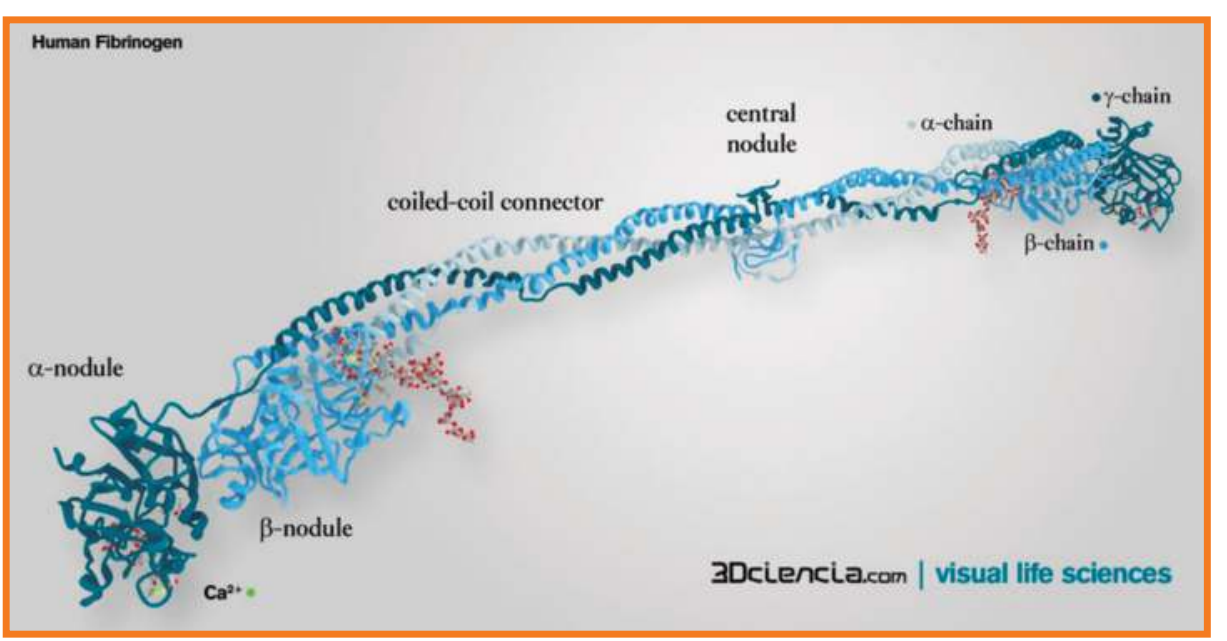

Image 1. Fibrinogen

A 52-year-old woman, scheduled for mediastinoscopy for lymph node staging of lung cancer. In the preoperative period, she was found to have:

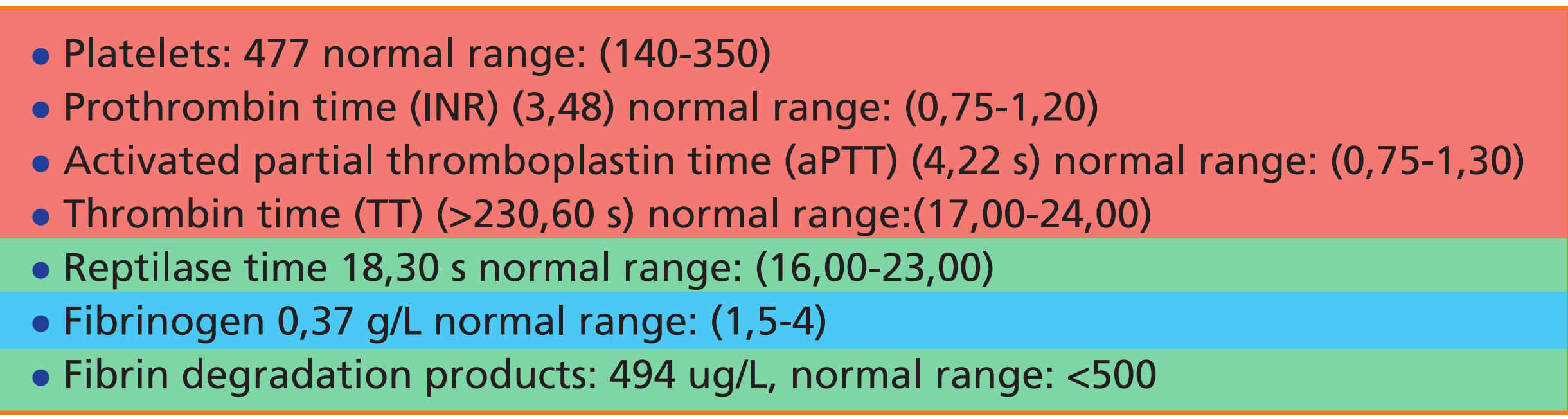

She denied easy bruisability, petechiae, purpura or ecchymosis. She had ten abortions in the past. Hemostasis Unit diagnosed an acquired dysfibrinogenemia with an inhibitor that produced a delay of fibrinopeptide $B$ release.

We performed a ROTEM ${ }^{\circledR}$ before and after the surgery and we noticed:

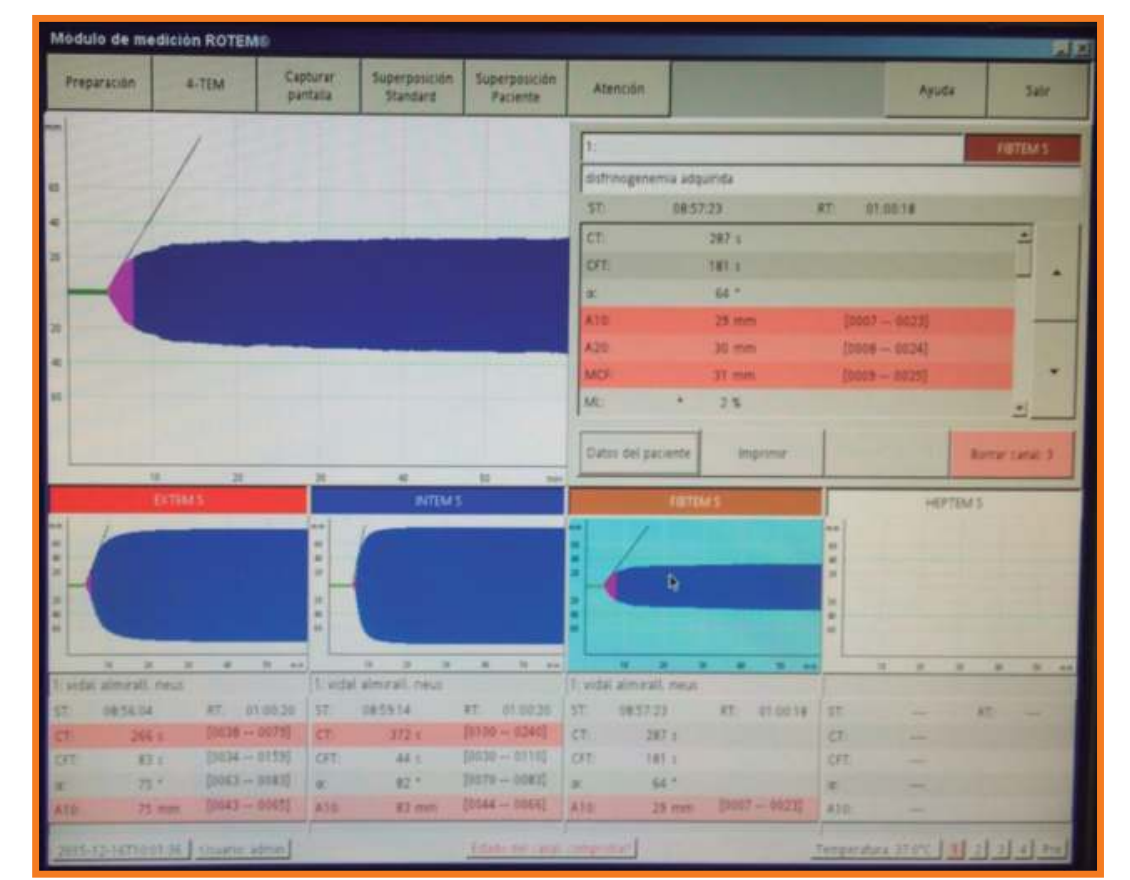

Image 2. Pre-surgery

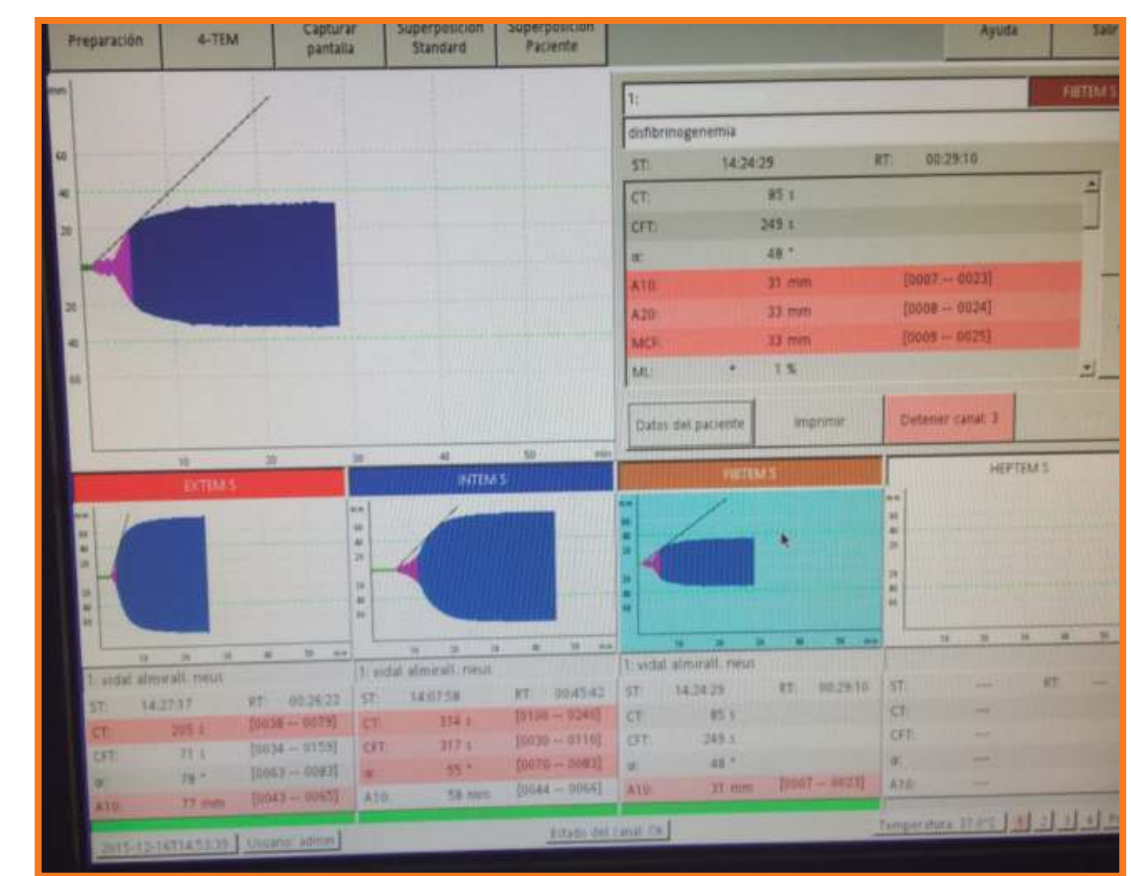

Image 3. Post-surgery

We administered fibrinogen (1g) previous to the surgery and it was performed without any complications.

\section{Discussion}

Most patients with dysfribrinogenaemias due to delayed relase of fibrinopeptide B do not have associated bleeding complications.

There are two potential explanations for the absence of haemorrhagic manifestations.

- Firstly, only a small amount of fibrinopeptide $B$ release is sufficient to influence the clotting process. During the formation of a clot after the action of trobin, only $10 \%$ of fibrinopeptide $B$ need be liberated.

- Secondly, any liberation of fibrinopeptide B enhances the rate and extent of lateral association and fibrin assembly but it is not necessary for clots themselves to form.

These two functional characteristics of fibrinopeptide B liberation explain how patients with defects in fibrinopeptide B liberation can have striking "in vitro" laboratory findings without evidence of clinical bleeding.

Thromboelastometry may help us during the perioperative period.

\section{References} 1. Nawarawong $\mathrm{W}$. The rate of fibrinopeptide B release modulates the rate of clot formation: a study with an acquired inhibitor to fibrinopeptide
B release. Br J Haematol 1991;79:296-301.

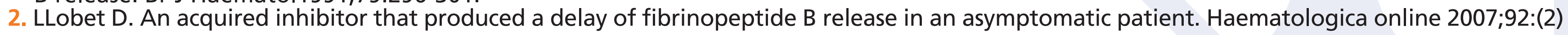

